has been associated with improvement in porphyric crises. Rank et al described neurological improvement after treatment with haemarginate in a 21 month old boy with a neurological crisis. ${ }^{2}$ This child then received a liver transplant and did well. Our patient showed no improvement with haemarginate treatment and ALA concentrations only returned to normal after liver transplantation. With the severe demyelination demonstrated preoperatively, it was not surprising that neurological recovery was slow.

Recently a novel treatment with 2-(2-nitro-4trifluoro-methylbenzoyl)-1,3-cyclohexanedione has been shown to inhibit the tyrosine degradation pathway with marked reductions in succinylacetone, ALA, and PBG. $^{3}$ Experience with this compound is at present limited it is not yet clear what side effects the treatment may produce and whether neurological crises and the risk of hepatoma will be entirely eliminated.

1 Mitchell G, Larochelle J, Lambert M, et al. Neurologic crises in hereditary tyrosinemia. N Engl f Med 1990; 322: 432-7. 2 Rank JM, Pascual-Leone A, Payne W, et al. Clinical and laboratory observations. Hematin therapy for the neurologic oratory observations. Hematin therapy for the n

3 Lindstedt S, Holme E, Lock EA, Hjalmarson O, Strandvik B. Treatment of hereditary tyrosinemia type I by inhibition of 4-hydroxyphenylpyruvate dioxygenase. Lancet 1992; 340 813-7.

\section{High dose methylprednisolone for painful sickle cell crises}

The management of pain in sickling disorders was discussed in Archives in August 1993 (69: 256-9). Now doctors in Texas (Timothy C Griffin and colleagues, New England fournal of Medicine 1994; 330: 733-7) have described their experience with the use of high dose intravenous methylprednisolone in painful sickling crises. They studied 56 painful episodes in 36 patients aged from 2 to 19 years. In a placebo controlled, double blind study with random assignment methylprednisolone was used in 26 episodes and placebo in 30 . The dose of intravenous methylprednisolone was $15 \mathrm{mg} / \mathrm{kg}$ of body weight (maximum $1.0 \mathrm{~g}$ ) given over 30 minutes soon after admission to hospital and repeated 24 hours later.

Episodes in which placebo was given necessitated intravenous or oral analgesics for a mean of 71.3 hours; those in which methylprednisolone was used necessitated it for a mean of 41.3 hours $(p=0.03)$. When seven patients who developed the sickle cell chest syndrome were excluded from the analysis the difference was more significant $(62.5 v 31.0$ hours, $\mathrm{p}=0.01)$. There is a suggestion that patients given methylprednisolone may be more likely to have further painful crises soon after discharge. Five patients were readmitted because of pain within eight days and of those four had been given methylprednisolone.

Clearly more studies are needed. High dose methylprednisolone may have a useful role but the possibility of rebound crises is worrying.

ARCHIVIST 